Prestige, Performance, and Social Pressure in Viral Challenge Memes: Neknomination, the Ice Bucket Challenge and SmearForSmear as Imitative Encounters

\title{
Abstract
}

This article examines social media challenges that emerged in 2013 , focusing on $\mathrm{Ne}-$ knomination, the Ice-Bucket Challenge and SmearForSmear. We suggest understand them as 'viral challenge memes' and manifest a set of consistent features that make them a distinctive phenomenon within digital culture. Drawing upon Tarde's (1903, 2010/1888) concept of the imitative-encounter, we highlight three central features: their basis in social belonging and participation, the role of prestigious people and groups in determining the spread of challenges, and the distinctive techniques of selfpresentation undertaken by participants. Based upon focus group interviews, surveys and visual analysis we suggest that viral challenge memes are social practices that diffuse in a wave-like fashion. Negotiating tensions between the social and individual, imitation and innovation, continuity and change, viral challenge memes are best thought of as creative practices, rather than sheep-like acts of conformity, and affirm the usefulness of analytical principles drawn from Tarde.

Key words: Neknomination, Ice-bucket challenge, Smear for Smear, viral challenge memes, digital culture, Tarde

Authors: Adam Burgess, SSPSSR, University of Kent at Canterbury; Vince Miller, SSPSSR, University of Kent at Canterbury; Sarah Moore, School of Social and Policy Sciences, University of Bath

Corresponding author: Adam Burgess, SSPSSR, University of Kent at Canterbury CT2 7NF a.burgess@kent.ac.uk 
Prestige, Performance, and Social Pressure in Viral Challenge Memes: Neknomination, the Ice Bucket Challenge and SmearForSmear as Imitative Encounters

Introduction

During the summer of 2014 just over 17 million Ice-Bucket Challenge (IBC) videos of people tipping water over themselves were shared on Facebook and viewed over ten billion times by more than 440 million people (Facebook, 2014). It was the global media event of the year. It also marked the emergence of a new form of participatory digital culture, one that we describe as the viral challenge meme (hereafter VCM). Other challenges followed, such as the characteristically celebrity-led ' 22 PushUp Challenge', intended to raise awareness of the high rate of suicide among American war veterans. These challenges urge members of an online community to construct their own version of something around an ever-evolving, collectively-produced format. While the speed at which they spread makes them akin to viral videos, the VCM is distinct in relying upon a nomination process that requires participants to contribute to and develop the format. The VCM's recipe for response - one that is at the same time variable and vague - is a central feature of the phenomenon, providing the means for self-expression, as well as a source of social belonging, participation, and even obligation.

Following Tarde $(1903,2010 / 1888)$, this article understands VCMs as imitative encounters, the parameters of which are created by digital culture. In such a context, extended social groups are more visible and the life-course of communicative social phenomena is simultaneously brief, intensive, and extensive. This article analyses these features of VCMs by drawing upon the results of an online survey $(n=211)$ and focus groups with nominees of three challenges $(n=55)$, all of which emerged between Janu- 
ary 2014 and February 2015: Neknomination, the Ice-Bucket Challenge, and SmearForSmear. Before setting out our methodology and findings, we trace the emergence of each of these challenges, introduce the concept of 'viral challenge meme', and sketch out our theoretical framework.

Viral Media, Memes, and Viral Challenge Memes

Coined by controversial biologist Richard Dawkins in The Selfish Gene (1976), a meme is any idea, behaviour, or skill that is transferred from one person to another through imitation and embellishment, be that through stories, fashions, inventions, recipes, songs, and even ways of ploughing a field or making a sculpture (Blackmore, 2000). Dawkins (1976) conceived of the meme as the cultural analogy to the biological unit of the 'gene'. Where genes replicate by inheritance, memes replicate by imitation (Schmidt, 2004). Thus, despite the impression that memes emerged recently with the advent of digital culture, the practice it describes is a fundamental feature of social life. McNeill (2009:84), for example, notes the importance of memes in traditional folkloric practices. At the same time, it would be a mistake to see online memes as simple reiterations of older, off-line memes. The Internet has accelerated the rate at which memes can be circulated and embellished, and has thus had a transformative effect on memetic practices. This in turn has prompted the growth of a body of academic literature that treats online memes as a discrete phenomenon.

One common claim within this body of literature is that digital culture blurs the distinction between producers and consumers, leading to a more open, democratic, and collectively-organised media environment. The results of this digital culture - threads, viral videos, memes - are less 'products' or 'goods' than fluid and malleable artefacts in continual construction and reconstruction amongst peers (Bruns, 2008). Wiggins and Bowers (2014), for example, argue that memes are artefacts of a participatory digital 
culture. In sketching out the parameters of this culture they usefully distinguish the memetic from the viral. Viral media, they point out, characteristically achieves shortlived but global popularity. They spread far and quickly, but are constrained in the scope they offer for innovation; the 2012 'Gangnam Style' dance video is an interesting example. By contrast, Internet memes tend to require more dynamic interaction. Thus where 'viral media' involves repetition, but little in the way of alteration, Internet memes are characterised by continual and deliberate alteration, parody and reworking. Thus Shifman $(2012,2014)$ suggests that memes are defined by the dual practices of imitation and remixing, and are therefore more fully expressive of participatory culture than viral media. The emergence of this aspect of digital culture has led Dawkins himself to suggest that ' $[t]$ he idea of the meme itself has mutated and evolved in a new direction' (Dawkins, cited in Wiggins and Bowers, 2014: 1889).

In recent years, a hybrid form of digital culture has emerged which combines the immediacy and impact of the viral with a process of innovation and change usually seen - albeit over a longer period - with memes. An important antecedent to this new phenomenon was the Harlem Shake, a participatory video meme which started in 2013 and involved people making variations of a music video and uploading it to YouTube. A year later, the emergence of the online challenge Neknomination marked an important stage in the evolution of participatory digital culture. Like the Harlem Shake, it was viral and memetic. Unlike the Harlem Shake, it involved a structure of direct nomination. Neknomination appears to have originated in Australia and, in its original format, required participants to video themselves 'necking' a pint of beer within 24 hours of being nominated and nominate others to do the same (Sumathi, 2014). The game then evolved into roughly two types. First, nominees chose fun, challenging, and often public locations to 'neck' their drink. For example, in videos made in early February 
2014 , two women both chose supermarkets as their venue, one riding a horse inside and the other stripping to her underwear (The Guardian, 2014).

The focus of the second main type of Neknomination challenge lay in participants' choice of drink which typically involved an unusual, and often daring, cocktail of liquids and other substances. With the focus here on the drink itself, videos were generally shot in mundane locations, typically the student bar or bedroom. A culture of excess and deviance was on display, and tales of resulting harm, even death, started to appear in the media. The Daily Mail (2014), for example, counted its third Neknomination death in mid-February 2014 and, as with much media commentary, framed the challenge in terms of the damaging consequences of peer pressure. Partly in reaction to the media alarm, Neknomination evolved further into nominations for 'random acts of kindness', referred to popularly as RAKnomination. Neknomination achieved viral status but, in part due to its ongoing permutation, its life-course was relatively long (see Figure 1, below).

The Ice-Bucket Challenge (hereafter IBC) took off some six months after Neknomination and achieved extraordinarily wide participation. Like Neknomination, it was based upon a game structure, with participants inviting others to take up the challenge. Unlike Neknomination, the IBC experienced a sudden wave of popularity and died away quickly (see Figure 2, below), for reasons that we explore in the analysis sections of this article. The IBC first emerged in 2013 in various minor celebrity stunts to encourage charity donations, and then, in 2014 , became specifically associated with the USbased charity for sufferers of amyothrophic lateral sclerosis (ALS). It was at this point 
- in the summer of 2014 - that the challenge became widespread, partly due to the participation of celebrities such as Bill Gates, Mark Zuckerberg, and George W. Bush.

The challenge was to tip a bucket of ice-cold water over oneself within 24 hours, in combination with, or instead of, a charitable donation. As with Neknomination, the IBC quickly acquired a life of its own. Ice was often dispensed with and it became a fun activity in which even children could become involved. The most striking feature of the challenge's evolution was its separation from the charity and charitable act to which it was originally linked. Whilst the ALS Association reported some $\$ 100 \mathrm{~m}$ of additional funding as a result of the challenge, it is clear that a significant number of participants did not see the act as necessitating a charitable donation. Estimates from the Charities Aid Foundation suggest that around 1 in 6 people in the UK participated in the IBC, but only $10 \%$ made a donation (Baton, 2014).

(Figure 2 here)

Neknomination and the IBC helped establish a new form of participatory digital culture. Indeed, it's striking that our focus group participants talked about these crazes as examples of a particular type of cultural practice. We too believe that social media challenges should be understood as a discrete phenomenon, despite their considerable variation. We suggest calling them 'viral challenge memes' (VCMs) as they aim for virality, are structured around a challenge, and require individuals to creatively interpret a format in a participatory fashion. 
After the success of the IBC, there was a proliferation of VCMs and this affected the meaning of participation. SmearForSmear is a case in point, and our third example in this study. This VCM was launched in February 2015 by Jo's Cervical Cancer Trust, a UK-based organisation that provides women with information about cervical cancer. The idea for the social media campaign was first suggested through a student competition - interestingly, before the emergence of Neknomination and the IBC - and was then developed in collaboration with a public relations company. The charity launched the campaign to coincide with cervical cancer awareness week, and used their networks to encourage a wide range of opinion leaders and supporters to take part in the challenge and produce the necessary momentum. The challenge involved people being encouraged to put lipstick smears on their cheeks, post a picture on social media using the 'SmearForSmear' hashtag - and here Twitter and Instagram, along with Facebook, were widely-used sites for posting. Whilst the campaign did not achieve the virality of our other two case studies (and didn't generate enough Internet traffic to generate a graph to show its life-course) it was highly successful from the charity's perspective, achieving significant mainstream media attention in the UK and internationally.

Theorising Viral Challenge Memes

Social things, which maintain and perpetuate themselves by the individual consciousnesses through which they evolve, are like an ocean wave, which crosses innumerable molecules and seems to animate them even while living from their force (Tarde, 2010/1888: 120).

Just as much as it calls for conformity, belonging, and a sense of social obligation, the VCM involves individual distinction and innovation. In this regard, it conforms very closely to Simmel's (1957) conception of fashion. For Simmel, fashion is a distinctively 
modern phenomenon, allowing us to mark ourselves out from others at the same time as necessarily setting limits to self-expression. It is, in a classic Simmelian formulation, conducive to individuality along certain lines, according to given prescriptions, and within specific modes. VCMs operate similarly: they set the parameters for expressions of individuality and establish a normal range for elaborating upon a given idea or style. What Simmel does not explore, and what is central to our work here, are the factors that affect participants' perception of the parameters and normal range for selfexpression, such as a feeling of not wanting to stand out, a pressure to do something 'new' (but still recognisable), and concerns about one's behaviour being deemed deviant.

The tension between conformity and individuality was also a fundamental concern for Tarde $(1903,2010 / 1888)$. A contemporary of Simmel, Tarde provided an alternative to the 'two step' discussion of the 'individual' and 'the social' that predominated in early sociological thinking. Instead, Tarde explained the social in terms of the dynamic relationship between continuity of actions and beliefs on the one hand, and innovation and change on the other. He saw the social as originating out of the emulative and imitative processes involved in everyday life, rather than the result of the deterministic structures of 'society' - what Durkheim referred to as 'social facts' (Durkheim, 2014/1895).

Sampson $(2012,2014)$ suggests that Tarde's micro-oriented sociology is key to understanding virality in the information age. For Sampson, the power of Tarde's approach lies in his concern with the collective force of action as it moves through social life. As the quotation at the start of this section indicates, Tarde saw 'social things' as having a movement akin to that of an ocean wave: they 'animate' and 'live from the force' of individual consciousnesses (Tarde 2010/1888: 120). Waves have their own momentum, 
can be dissipated or amplified, and even, on occasion, merge with other waves. Similarly, social phenomena, such as fads, fashions, or even, crimes (a particular interest for Tarde), whilst originating in specific individual actions, gain their own momentum beyond individuals, moving from one person to another, eventually involving (and creating) social masses. In Tardian terms, these are not discrete events; waves of communication, behaviour, and belief leave a residue and become diffused.

Whilst, then, Tarde saw the interaction of two individual consciousnesses as the primary social fact - as he put it, [e]verything comes from the infinitesimal and everything returns to it' (Tarde, 2012/1895: 11) - he also believed that individual preferences and decisions are shaped in an ongoing fashion by the ebb and flow of social life. Durkheim saw Tarde as psychological in orientation (Abrutyn and Mueller, 2014: 698). In fact, Tarde continually discounted the possibility of the pre-social individual. Instead, he saw the individual as re-working the social in her interaction with others. One corollary of this is that individual elements reflect the social whole, and vice versa. In this, Tarde was influenced by modern chemistry and physics. Indeed, Candea (2016: 12) suggests that in blurring the distinction between the self-contained individual and the group, Tarde subscribed to the modern doctrine of monadology, the idea that the smallest elements of an entity constitute a microcosm.

For Tarde, the relationship between the individual part and the social whole is made possible by imitative interaction. He argued that it is this, rather than social structure, that provides the basis for the socialisation of the individual (Tarde, 1903). In turn, the social is the result of a 'career' of imitations (Marsden, 2000). Imitation here does not refer to a simple process of observation and mimicry, but to something requiring a deep knowledge of the social. Thus, to Tarde, the objects of imitation are not, as one would perhaps assume, the actions themselves, but the meanings, ideas, beliefs and 
desires which those actions make manifest (Schmidt, 2004). In this respect, imitation involves individuals being open - consciously or not - to the internalisation of the beliefs, values, and desires of others. Tarde allows, then, for some degree of choice in imitative interaction, and suggests that cognitive, moral, aesthetic, and affective factors influence whether an idea, behaviour, belief or value will be accepted and imitated. Again, such 'choices' are not necessarily individual ones, as Tarde proposes that the criteria used to judge the adoption of a practice (in terms of individual preferences, beliefs or values) are not our own, but taken from others (Schmidt, 2004).

In an attempt to clarify Tarde's conception of participation, Arbrutyn and Mueller (2014: 705-14) identify five core factors involved in the decision to engage in an imitative encounter:

- Logical imitation: a practice is more likely to be adopted if it is perceived by the individual to be useful, true, or beneficial to her/him.

- Customary imitation: a practice is more likely to be adopted if it fits in with existing traditions and is not seen as 'alien' or incommensurate with existing values or norms.

- Emotional imitation: a practice is more likely to spread if it manages to create emotional intensity or resonance.

- Prestige imitation: practices are more likely to be adopted if they are connected with prestigious, powerful, or well-thought of persons and social groups.

- Propinquity and imitation: practices are more likely to be adopted if they appear to emanate from those emotionally, physically or situationally close to us.

This typology has proven useful in explaining our findings, though the analysis below by no means seeks to produce a model of imitation based on these factors. Our analy- 
sis is instead guided by the more general theoretical principles found in Tarde's work. Using Tarde as a point of departure, then, we examine how VCMs might operate as waves of imitative encounters that contain elements of mass conformity and imitation, while at the same time demonstrating elements of individual choice, innovation and creativity. In adopting this approach, this article eschews the metaphors of virality and contagion that are often employed to understand digital culture, implying, as they do, a lack of agency and innovation on the part of individuals (Blackmore, 2000). Before considering these ideas more fully, we outline our methodology.

Case Study Selection, Methods, and Analysis

A fundamental feature of VCMs is their 'here today, gone tomorrow' quality; the pleasures (or not) of participating can only really be studied whilst the challenge is 'live' and still has currency. This presented us with a set of practical and methodological challenges. For one thing, it meant that we had to conceive and launch each round of the study within a seven day period. The first round of the study focused on Neknomination. After that was complete, we constantly monitored new challenges as they arose on social media. In selecting further case studies we had to balance the need to 'catch' a VCM early in its life-cycle against the risk that in initiating research before a challenge had matured we would be investing energy in one that made little impact.

The scale and virality of the IBC quickly became apparent and we launched the survey for what would become our second case study within five days of the VCM becoming widespread. We had greater difficulty in deciding upon our third example. VCMs proliferated from late 2014 onwards, and this meant there were lots of potential case studies, but a higher risk of choosing a challenge with limited participation. Our third 
case - the SmearForSmear campaign - launched in February 2015, did not have anything like the impact of our other two case studies. It nonetheless served as an interesting comparative focus, not least as a VCM where nominees felt markedly less pressure to participate, for reasons we discuss below.

For each round of the study, we used an online survey and focus groups to generate data, and produced a typology of images/videos based on an unstructured group analysis of online posts. Potential concerns of confidentiality and anonymity informed the research design, which was approved by the University of Kent research ethics committee. For Neknomination and the IBC, we invited anyone who had been nominated to take part in the study. As a consequence, a large proportion $(54 \%, 100)$ of survey respondents to the first and second round of the survey were those who had turned down an invitation. This shaped the construction of our focus groups, as we decided to hold separate sessions for participants and abstainers. For the SmearForSmear survey, we asked anybody who had completed a challenge to take part in the study. This was because the nomination process for this VCM was often indirect - for example, Instagram-users posting SmearForSmear images tended to issue the challenge to all of their followers.

The survey gave us the opportunity to gain a snap-shot view of participants in each challenge. A significant proportion of respondents $(58 \%, 82)$ lived in the South of England at the point of carrying out the survey, but $10 \%(22)$ of respondents lived outside of the UK, including Hong Kong, Singapore, Kenya, Canada, and Spain. We used Bristol Online Surveys to produce the survey, posted the link on the project's dedicated Facebook page, and promoted the survey through our own professional and social networks. We received a total of 211 useable survey responses: 69 for Neknomination, 
102 for the Ice-Bucket Challenge (IBC), and 40 for SmearForSmear. Each round of the survey used the same set of core questions concerning nominees' reasons for deciding to undertake the challenge or abstaining and their experience of participating, including their feelings on being nominated and how they interpreted the challenge. We produced a dataset in SPSS, and carried out a quantitative analysis, testing for relationships between gender, feelings on being nominated, age and participation, status of nominator and nominees, and experience of 'peer pressure'.

We also carried out eight focus groups, and these allowed us to probe nominees about their experiences and motivations. Four groups focused on Neknomination nominees $(\mathrm{N}=26)$ and four on IBC nominees $(\mathrm{N}=29)$. We used a snowball sampling technique, inviting students at the University of Kent and Canterbury Christchurch University to participate, and then asking them to bring along friends who had been nominated. This meant that our sample was relatively homogenous, with the majority being middleclass, white, 18-24 year olds. Representativeness was, though, never a core concern in undertaking the focus groups. Instead, they provided us with in-depth accounts of the pressures involved in accepting or declining a challenge. The next section deals directly with these issues, and examines the bases for nominees' decisions to participate in or abstain from a VCM.

To Imitate or Not? Balancing Conformity and Choice

A significant minority of the survey respondents reported feeling pressurised to takeup an invitation to contribute to a VCM, with marked differences between the surveys. Only one of the 40 SmearForSmear respondents reported feeling any pressure to take part. In contrast, $32 \%$ of the Neknomination respondents and $37 \%$ of the IBC respondents reported feeling pressure to participate. The focus groups gave us the opportuni- 
ty to examine the bases for this sense of pressure. Here we found that pressure tended to reside in nominees' sense that in contributing to a VCM they had to do something new and distinctive without going too far or setting the bar too high for subsequent nominees. We return to this point in the final analysis section. For now we want to emphasise that few of our focus group participants perceived VCMs to be purely conformist; for most, the decision to participate tended to involve both a sense of obligation and the exercising of personal choice. Take, by way of example, the explanation offered by one IBC nominee:

I did the no makeup selfie challenge. I don't know, sometimes I feel like it's peer pressure, I feel like I have to do. I was actually nominated quite a lot of times for the no makeup challenge so I just kind of did it really...I think it's because I actually agree with the point they're trying to make, like I think it's a liberation for women (Respondent 4, IBC group 1).

Thus, for the majority of the focus group participants, the decision to take part or abstain was an ambivalent one.

There were two distinctive groups of nominees for whom this was not the case. The first focus group with neknominees contained one of these groups. These participants resisted the idea that Neknomination was a new practice. Instead, they saw it as consistent with a larger, particularly university student and sport club, tradition of drinking games. Thus, their decision to participate was based on the Tardian norm of customary imitation. Participants tended to nominate others quite selectively, according to who might be "up for it", as one put it, suggesting that, for this group, nominating someone served as a form of social approval. To be included in the game was evidence of popularity or appreciation by others, as one was effectively 'chosen' to participate. 
Indeed, some suggested that particularly entertaining performances made them respect acquaintances more. In this sense, these performances contributed to the shifting boundaries of social exclusion and inclusion, and participation, if one was nominated, was a given.

The abstainers of the third focus group with Neknominees were acutely aware of the social ordering effects of VCMs. They saw themselves as social 'outsiders' and experienced being nominated as straightforward social pressure which was difficult to negotiate. For them, the decision to decline an invitation was straightforward. All the same, they recognised the potential impact on their reputation and social status. Several hid the nomination on their Facebook timeline. One strongly reacted against Facebook itself and the social pressure with which it is synonymous. A handful of participants in other focus groups, all of them abstainers, concurred. One contrasted the authentic social experience of drinking games with the artificiality of Neknomination, which was done "just to get some likes on Facebook and try and be popular" (Respondent 8, Neknomination group 3). Several participants couched their decision to abstain in terms of concerns about how their family and potential employers would see them. The following quotation is characteristic:

I didn't do the Neknomination. I was actually nominated twice...but I didn't do it as I was applying for several jobs as the time, so I kind of have that kind of, you know 'maybe they're going to go through my Facebook and that may not be the best image to display out there'. So I didn't do it. (Respondent 3, IBC group 1)

Despite the clear concern about peer pressure amongst this group of participants, it's striking that all of those who perceived VCMs in these terms were abstainers. In other words, we did not hear from anybody who had felt the effect of peer pressure to be so 
overwhelming that they felt forced to participate. There were, though, more subtle pressures to participate, and we turn to consider these next.

Prestige, Propinquity, and Timing

Prestige imitation, the Tardian notion that practices are more likely to spread if associated with well-thought of persons or social groups, is a central part of the diffusion process of VCMs. This was the case with all of the VCMs studied, but was particularly marked in the IBC. When asked to explain their decision to participate, a number of IBC nominees told us that the role of celebrities had been key. The following quotation is characteristic:

Like...I see Bill Gates, because you always sort of see him like a quite... he's not that kind of celebrity... he's, you know, a CEO, just really proper, and to see him doing [the IBC], that's quite something. And then it spreads out to other celebrities that you might like and then it's all about 'yeah I want to like do the same thing as him' and that kind of thing. (Respondent 4, IBC group 1)

For most participants, seeing friends and family take up this celebrity-led practice introduced a form of social obligation. Propinquity, in other words, was a key ingredient in their decision to participate:

I think as well because you see your friends actually doing it as well. Like you see your friends, like you feel more comfortable doing it. Like I guess with a celebrity you like think 'oh, maybe l'll do that', but there's a bit more distance in that whereas when it's your friends and people you actually know doing it, I think it encourages you to do a bit more. (Respondent 4, IBC group 1) 
Interestingly, we found that this subtle pressure of being nominated by friends and loved ones sometimes made all the difference in nominees' decision to participate:

I felt more [pressure] with Neknomination because someone close to me nominated me, but not with the water one at all... (Respondent 6 , IBC group 3 ).

Thus, a key question for our respondents and focus group participants was who made the nomination and what they meant to the nominee, but also, interestingly, how early in the cycle they did so. For most, being nominated early was preferable. Some Neknomination abstainers reported that they would have accepted the challenge had it been made earlier when it involved simply drinking a pint. One explained:

By the time I got nominated everyone had started instead of just doing just simple pints it was gin with vodka and rum and whisky and baby food and all this sort of thing. (Respondent 8, Neknomination group 3)

The social implications of being 'late to the game' were also factors that shaped nominees' decisions to participate. Several survey respondents who turned down a nomination to do an IBC mentioned that they felt the craze was dying out and they were too late to join in. Similarly, in one IBC focus group, a participant explained that a nomination had reached her late in the challenge's life-cycle, and this had made her feel leftout:

Yeah, I think like if you're not in the initial wave of people who do it then you're kind of just stringing it along and, I don't know, you kind of get looked at weird- 
ly...You know people are sick of looking at it now and you don't want to be the person who has to put that in front of people. (Respondent 2, IBC group 3).

Our findings further suggested that a VCM comes to be seen as passé and increasingly empty of meaning during the final stage of its life-cycle. Some saw the cause itself as becoming tainted in the process. Thus, one focus group participant described the IBC as "shedding" its original purpose and becoming "stripped down". She went on to explain that:

I think the [...] whole thing kind of changed from 'you should do it because it's a nice cause' and that kind of stuff, to 'you'll be helping out', to 'do it! (Respondent 3, IBC Group 1)

For another IBC nominee, the decision to abstain was due to the fact that she was nominated once the connection with the original charity (ALS) had weakened and the challenge had become, to her mind, an "empty gesture". Echoing this sentiment, a fellow IBC nominee commented that:

...these trends find me so late in the process that I'm so frustrated and fed up with them by the end. I think I knew about the ALS ice bucket like in June so by the time I got nominated at the end of August I was like 'this has lost all its meaning'. (IBC group 1 Respondent 2)

All of this indicates that the decision to take part in a VCM is not only about who invites you to take part, but also about when you are asked to contribute. Good timing is essential. Early nomination brings prestige, and thus more impetus to participate, whereas late nomination can bring the opposite effect. In turn, the stage at which 
someone is nominated can create problems in producing an adequate performance. We turn now to consider more fully the pressure involved in participating in VCMs.

Sociality, Individuality and Creativity: Innovating Through Imitating

It's just like on Facebook you don't really take it so seriously. So, I think the only pressure was kind of, when you first get it and you're like 'oh I might do it' and then you try and think of an idea, and then you can't think of anything good enough. That's kind of the only...pressure you get I guess. (Respondent 4, IBC Group 3)

As discussed in the first analysis section above, the focus group participants who took up an invitation to participate in a VCM tended not to conceive of their performances in terms of straightforward peer pressure. When this was mentioned, respondents tended to indicate a retrospective concern about having "followed the crowd" rather than an experience of coercion. Instead, they tended to speak of a more subtle social pressure to innovate: to demonstrate that one was able to intuit the rules of the game, distinguish oneself, and at the same time work within the shifting parameters of the challenge - to think of something "good enough", as the participant quoted at the start of this section puts it. This sentiment was echoed by participants in other focus groups:

I was a little bit scared to start with. Not scared but...trepidation because I got caught quite early on and all the ones l'd seen before were quite good and, you know, people were doing really extravagant things but I just thought there's no way I can do a massive alcoholic mix of ridiculous substances so my pint was 
quite straightforward but I tried to make mine funny so I did mine in the bath. (Respondent 1, Neknomination group 2)

A number of participants framed the challenge as an opportunity to show a different side to themselves, gain others' respect, and make a mark. The performance itself both its timing and content - was determined by a wide range of factors, including the person who had set the challenge, the need to innovate, and the nominee's sense of self-identity. For example, one neknominee concluded that the challenge required the "either lots of alcohol or [something] grotesque". A lack of available alcohol available meant he "went for grotesque". In the end, the participant opted to make his video “interesting" by including "loads of healthy things such as smoothies and fruit". Pleased with the fact that the cocktail reflected his identity amongst his peers as someone interested in health and fitness, the participant also felt that he had satisfied the need to make his contribution sufficiently distinctive. In the focus group, he devoted considerable time to outlining the implicit rules of performance for Neknomination, and it was the relationship to others' contributions that seemed to matter most. This emerged as a central theme in focus group participants' responses. The importance of fitting in with existing performances was succinctly expressed by a neknominee in our second focus group:

I didn't want to do anything too impressive, but I didn't want to do anything as simple as a pint - that's the way I looked at it (Respondent 4, Neknomination group 2).

This view of participation closely resembles Tarde's conception of the imitative encounter: performances should avoid being singular at the same time as being different enough. Our focus group participants found the latter requirement particularly tricky. 
As a Neknomination participant from a different focus group put it: the point is not to simply "do a bit more" than your nominator; the performance must make a qualitative contribution to the overall challenge. Another participant added that the point of contributing to a VCM is not to outdo someone. The key thing, she suggested, was to embrace the spirit of the challenge by adding what you can, according to your limits.

Such comments reflect the fact that, for many of our participants, VCMs were seen as fundamentally consensual. For a handful, predominantly our male participants, participation was directed more towards achieving personal distinction. Tellingly, several described VCMs as "competitions". In line with this vision, a number of focus group participants for both Neknomination and the IBC reported making what could be described as short films, complete with plots, characters, and often inside jokes, in response to nomination. The most extreme Neknomination performance detailed in the focus groups was carried out by a young man who produced a "Bear Gryls" type video, set in the woods and involving him drinking a mixture of his own urine, locusts, a mouse foetus, tree nectar, and bottles of wine and rum. The performance was consistent with his identity amongst his peer group as someone who is "known for being up for a bit of anything", and his stated aim was to "set the bar...try and top this!"

Very few VCM performances 'set the bar' and, in turn, very few nominees aspire to be the person who does so. What most nominees, including this one, share is a keen sense that their performances should reflect their particular talents, self-identity, and place within their peer group. This helps explain why, for many of the focus group participants, Neknomination was not about alcohol consumption per se, but instead about the interacting factors of performance and participation: 
The challenge for me wasn't even the drink; it was like let's see, you know, how creative and how funny it can be (Participant 5, Neknomination group 2)

Indeed, it is of note that, amongst our focus group participants, not being able to come up with something interesting enough was the second most common reason for not contributing to a VCM (after circumstantial factors, such as being ill, busy, or hungover).

Focus group participants also described the IBC as an opportunity for creativity, but found it harder than Neknomination participants to distinguish their performances. As one IBC nominee put it, with characteristic frustration:

... someone would do it and they'd want to do it in an interesting way and if you just tipped it over your head you were like boring, but people had to find an interesting way to do it to stand out. (Respondent 5, IBC group 2)

The difficulty in producing an innovative IBC performance lay partly in the sharp increase in the volume of nominations for this challenge, leading to individual contributions being easily drowned out. As another IBC nominee put it, “you can't really be a bit different when everyone's doing it" (Respondent 6, IBC group 2). The rapid saturation of social media with IBC videos was clearly a factor in this sense of frustration, as was the fact that the challenge itself was also generally felt to contain limited scope for creativity. For some, the IBC was principally a moral act, and participation a matter of obligation. This meant, in some cases at least, that the performance itself could become entirely formal and ritualistic. One focus group participant confessed to cheating by warming the water, but commented that she had sent money to a charity and this was "surely the more important thing". 
For some of the focus group participants, the moral nature of the challenge somewhat constrained the range of permissible performances, with overly showy or selfindulgent performances seeming at odds with the wider 'good cause'. At the same time, the point, as with Neknomination, was to do something slightly (but obviously) different to the nominator. It is perhaps unsurprising, given this tension, that the IBC nominees were more likely than the Neknomination participants to say that they felt a significant amount of pressure in producing a performance: "far too much pressure", as one nominee who filled in the survey put it. But again, this 'pressure' consisted of a perceived need to produce something that concomitantly met the brief, distinguished the performer, but left room for others to join the game. Timing, again, was key, as indicated by a participant who was nominated very early in the VCM's life-cycle:

I thought it was a laugh and because I knew how early in the chain I was, I was like well I just have to do something pretty simple and then the next person after me has to worry about doing something to beat what I did. (Respondent 2, IBC group 2)

The quotation draws our attention again to the fact that some VCMs - notably Neknomination and the IBC - undergo significant changes during their life-course. By contrast, others such as SmearForSmear remain relatively fixed in format and meaning. We found that the success and spread of these VCMs were partly dependent upon the nature of the challenge itself, that is, the degree to which it can be elaborated upon and, related to that, the possibility for the meaning of the act being broadened or co-opted. The scope for innovation in the act of smearing lipstick is relatively limited when compared with the range of possibilities in 'necking' something. This lack of improvisational scope with SmearForSmear was bound up with the fact that it retained its set meaning as a vehicle for raising awareness of a life-saving procedure. It is there- 
fore unsurprising that a significant proportion $(50 \%)$ of the SmearForSmear participants who responded to our online survey had a personal involvement with cancer or with the campaign itself.

SmearForSmear remained, throughout its life-cycle, an act of solidarity aimed at awareness-raising, where what one did was secondary to making a point. By contrast, there was no 'point' to Neknomination, other than actually doing it. As a consequence, this VCM afforded the greatest scope for innovation. Crafting an entertaining performance was central, and this drove a process of change. The IBC also contained enough possibility for evolution, both in terms of its format and content-meaning. These features were key to the wide diffusion of both of these VCMs.

\section{Concluding Discussion}

Viral challenge memes have been criticised by the mass media as being both narcissistic and mindlessly conformist. These seemingly contradictory claims point to a fundamental tension in social life between the influence of the social on the one hand, and, the individual need to adapt, create, and innovate according to personal circumstances and preferences, on the other. Returning to Tarde, VCMs demonstrate that social life involves both imitation and innovation. In this respect, concern over peer pressure with regards to challenges such as Neknomination are misplaced. The analysis above suggests that VCMs are better thought of as creative and inclusive challenges, rather than sheepish acts of conformity. Pressure plays a part, but it resides, in most instances, in the creative challenge of adding something new and distinctive, at the same time as keeping to a (constantly changing) format and sustaining the challenge so that others can contribute. Participating in a VCM involves adding to a social practice that 
diffuses in a wave-like fashion, and it requires contributors to have an intuitive social sense of the challenge's permutations, life-cycle, and currency.

Using Tarde's $(1903,2010 / 1888)$ theory of imitation as a conceptual backdrop, this paper has attempted to provide a better understanding of VCMs as a practice. VCMs manage, through the activation of social connections and resonances, to gain a momentum of their own which at times can seem unstoppable. The factors that determine whether a challenge will achieve such momentum are, though, difficult to manufacture, and it is notable that attempts to replicate the spread and salience of the IBC have failed. For Tarde, five principles of imitation determined the successful diffusion of social practices: imitation is more likely if it has a logical, customary, or emotional basis, if the act in question is associated with prestigious groups and individuals, and if there is sufficient propinquity to the originators of an act (Arbrutyn and Mueller, 2014). Our analysis indicates that each of these is an important factor in the dissemination of VCMs. Prestige imitation, for example, helps explain the extraordinary success of the IBC, not only in terms of associating certain practices with prestigious or respected people, but a further prestige gained in terms of being nominated early to participate in the practice. Our data also points to the role of emotional imitation, with respondents tending to describe their experience of being nominated in emotional terms, as prompting happiness, amusement, excitement, and, for those who felt that they had been nominated too late, frustration. Our participants were also clearly motivated by propinquity, in the sense that this was a social practice which was transferred between close friends, teammates, and family members. Indeed, it is generally through these close ties between people that participation in VCMs acquire meaning.

We also found that the acceptance of a new VCM is partly dependent upon perceived continuity with previous phenomena. Neknomination shared characteristics with tradi- 
tional drinking games, and the widespread participation in the IBC was, in turn, partly dependent upon Neknomination having established the VCM as a social practice. These are not, in other words, entirely new practices, but instead involve customary imitation. Finally, consistent with the principle of logical imitation, we found that participation in VCMs tends to be based on a reflective consideration of the perceived personal benefits of taking part, rather than mindless conformity to peer pressure. This frequently involves weighing the reputational risks of contributing too late in the challenge's life-cycle and producing an excessive performance. We suggest, then, that here logical imitation involves an intuitive sense of what constitutes the normal range for a performance, the social risks of going too far, and the broad level of approval for a practice. For most of participants, negotiating these boundaries and tensions produced an enjoyable, creative and fleetingly shared moment. The latter point suggests another important feature of participation, namely an overarching desire to be part of the social. As one neknominee put it:

I feel like sometimes with our generation we want to feel part of a movement. We haven't really had a great war to be a part of so be part of a social craze, it's good, lasting, you know, for a limited time only be part of this little click, or this flash mob, or this thing. (Respondent 3, Neknomination group 4)

It is, we think, Tarde's work that best makes sense of this distinctive, wave-like sociality - its spread, form, and the pleasures it affords.

\section{Acknowledgements}

Emma Cooke for her help in organizing focus groups and monitoring memes. Hotwire PR for their graphs monitoring meme impact. 


\section{Funding}

Research was carried out with the support of the faculty research fund in SSPSSR, University of Kent 
References

Abrutyn, S., \& Mueller, A. S. (2014) 'Reconsidering Durkheim's assessment of tarde: formalizing a tardian theory of imitation, contagion, and suicide suggestion', Sociological forum 29 (3): 698-719.

Baton C (2014). "Ice bucket challenge: One in six Britons took part - but only $10 \%$ donated". The Independent, 12 September. Available at:

http://www.independent.co.uk/news/uk/home-news/ice-bucket-challenge-one-in-sixbritons-took-part-but-only-10-donated-9729991.html

Blackmore S (2000) The Meme Machine. Oxford: Oxford University Press.

Bruns (2008) Blogs, Wikipedia, Second Life and beyond: From Production to Produsage. New York: Peter Lang.

Candea, M. (2016) The Social after Gabriel Tarde: Debates and Assessments (2 ${ }^{\text {nd }}$ edition). London: Routledge.

Daily Mail (2014) 'This is how you drink': Rash boast of Nek Nominate man, 20, who downed two PINTS of gin and died four days later, (16 February) Available at: http://www.dailymail.co.uk/news/article-2560680/Salesman-British-victimNekNominate-craze-downing-two-PINTS-gin-posting-video-internet.html Dawkins, R. (1976). The Selfish Gene. New York: Oxford University Press. 
Durkheim, E. (2014/1895). The Rules of Sociological Method: and Selected Texts on Sociology and its Method. New York: Simon and Schuster.

Facebook (2014). The Ice Bucket Challenge on Facebook.

http://newsroom.fb.com/news/2014/08/the-ice-bucket-challenge-on-facebook/

The Guardian (2014) 'Woman rides horse into supermarket in 'Neknomination' challenge' (5 February) Available at:

http://www.theguardian.com/world/2014/feb/05/woman-horse-supermarket-

$\underline{\text { neknomination-challenge }}$

Marsden, P. (2000). Forefathers of memetics: Gabriel Tarde and the laws of imitation. Journal of Memetics-Evolutionary Models of Information Transmission, 4(1), 61-66.

McNeill, L.S. (2009) 'The End of the Internet: A Folk Response to the Provision of Infinite Choice'. In Folklore and the Internet: Vernacular Expression in a Digital World. Trevor J. Blank, ed. Pp. 80-97. Utah State University Press.

Sampson, T. D. (2012). Virality: Contagion Theory in the Age of Networks. University of Minnesota Press.

Schmid, H. B. (2004) 'Evolution by imitation: Gabriel Tarde and the limits of memetics'. Distinktion: Scandinavian Journal of Social Theory, 5(2), 103-118.

Shifman, L. (2012) 'An anatomy of a YouTube meme', New Media \& Society 14(2): 187203. 
Shifman, L. (2014) Memes in Digital Culture. Cambridge, MA: MIT Press.

Simmel, G. (1957) 'Fashion', American Journal of Sociology, 62(6): 541-58.

Sumathi R (2014) 'How the Ice-bucket Challenge Got Its Start' Wall Street Journal, 14 August. Retrieved 30 September 2014. Available at: http://www.wsj.com/articles/howthe-ice-bucket-challenge-got-its-start-1408049557

Tarde, G. (1903) The Laws of Imitation. New York: Henry, Holt and Co.

Tarde, G. (2010/1888). Gabriel Tarde on Communication and Social Influence: Selected Papers. University of Chicago Press.

Tarde, G (2012/1895) Monadology and Sociology. Melbourne, Australia: Re Press.

Toews, D. (2003). The New Tarde Sociology After the End of the Social. Theory, Culture \& Society, 20(5), 81-98.

Wiggins B and Bowers G (2014) 'Memes as genre: A structurational analysis of the memescape', New Media and Society, pre-print publication.

\section{Author Biographies}

Adam Burgess is professor of risk research at SSPSSR, University of Kent. He is an inter-disciplinary scholar, working around themes of risk and uncertainty.

Vincent Miller is a Reader in Sociology and Cultural Studies at the University of Kent. He has written several articles and books on various aspects of digital culture.

Sarah Moore is a Lecturer in Sociology at the University of Bath. Her research focuses on the mediaten several articles and books on various aspects of digital culture. of the media. 


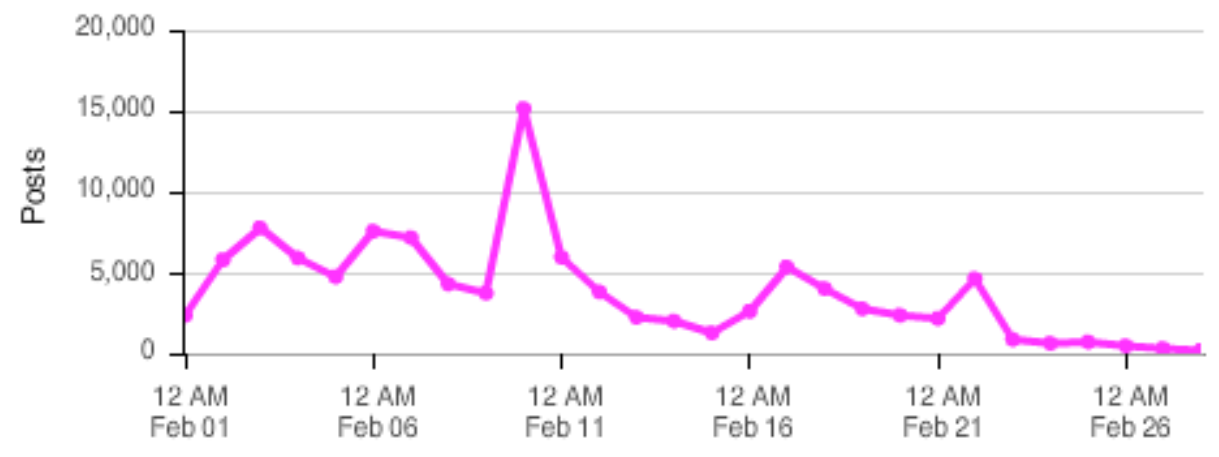

neknominate

Figure 1 : Neknominate social media posts. Source: Hotwire PR

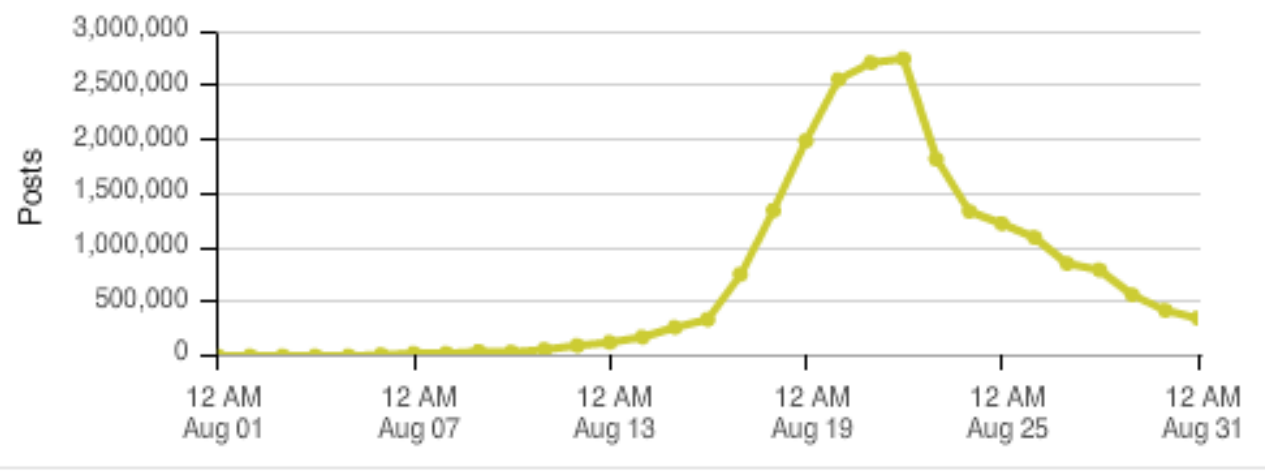

icebudketchallenge

Figure 2: Ice Bucket Challenge social media posts. Source: Hotwire PR 